\title{
DETERMINATION OF IRON COLLOID SIZE DISTRIBUTION IN THE PRESENCE OF SUSPENDED CELLS: APPLICATION TO IRON DEPOSITION ONTO A BIOFILM SURFACE
}

\author{
WAIHUNG LO', YARROW M. NELSON', LEONARD W. LION'*, \\ MICHAEL L. SHULER ${ }^{2}$ and WILLIAM C. GHIORSE ${ }^{3}$ \\ 'School of Civil Environmental Engineering, ${ }^{2}$ School of Chemical Engineering, and \\ ${ }^{3}$ Section of Microbiology, Cornell University, Ithaca, NY 14853, U.S.A.
}

\begin{abstract}
Transport and deposition of colloidal $\mathrm{Fe}, \mathrm{Mn}$ and $\mathrm{Al}$ oxides play key roles in the cycling of toxic transition metals in aquatic environments because these colloids strongly bind transition metals. Further, attachment of biological cells and biofilm growth on surfaces can indirectly affect toxic metal distribution by influencing the deposition of colloidal oxides to surfaces. To elucidate the mechanisms governing these processes, deposition of colloidal oxides onto surfaces must be evaluated in the presence of suspended and adherent bacterial cells. Both particle size and concentration are expected to influence deposition. An experimental protocol was developed to determine the size distribution of iron colloids in mixtures with suspended cells. A Ti(III) reagent was used to reduce and dissolve colloidal Fe(III) from mixtures containing both suspended cells and Fe colloids. The size distribution of $\mathrm{Fe}$ (III) colloids in the original solution was then determined from the difference between size distributions before and after dissolution of $\mathrm{Fe}$ with $\mathrm{Ti}(\mathrm{III})$. The Ti(III) reagent dissolved over $95 \%$ of the $\mathrm{Fe}$ colloids without altering the size distribution of suspended bacterial cells, and the method accurately determined the size distribution of $\mathrm{Fe}$ colloids added to cell suspensions. The applicability of this protocol was tested by applying it to a study of the deposition of $\mathrm{Fe}$ (III) oxide particles onto glass surfaces with and without biofilms of the bacterium Burkholdaria cepacia 17616. Experimental results using a laboratory biofilm reactor indicated that the deposition rate of $\mathrm{Fe}(\mathrm{III})$ colloids was not significantly affected by the presence of $B$. cepacia biofilms or by the presence of previously deposited $F e$. However, deposition of $F e$ to reactor surfaces other than the glass surfaces may have interfered with the analyses, and atomic absorption measurements showed a slight increase in Fe deposition onto glass surfaces with biofilms present. Fe deposition to the composite of all reactor surfaces increased with increasing colloidal particle size, indicating a dominance of interception and/or sedimentation in controlling $\mathrm{Fe}$ deposition on surfaces in the biofilm reactor.
\end{abstract}

Key words -adsorption, bacteria, biofilm, bioreactor, colloids, deposition, iron(III) oxyhydroxide, reductant, size distribution, titanium, transport

\section{INTRODUCTION}

Adsorption of toxic transition metals to metal oxides, present as suspended colloids or as surface coatings, is a dominant factor governing trace metal distribution and mobility in aquatic systems (Kruaskopf, 1956; Jenne, 1968; Turekian, 1977; Lion et al., 1982). Therefore, the distribution of colloidal oxides and the deposition of these oxides onto surfaces warrants examination. Colloidal oxides are expected to be influenced by suspended organic material via flocculation, and the deposition process is expected to be influenced by surface modifications by biofilmforming organisms. Attached cells in biofilms are frequently embedded in an extracellular polymer matrix of microbial origin, forming a tenaciously- bound surface coating that can significantly modify the metal-binding properties of the original surface (Davis and Leckie, 1978a; Lion et al., 1988; Nelson et al., 1995). While Mn oxides are deposited by active biological processes under oxic and suboxic conditions, colloidal Fe oxides can be deposited by both active and passive processes depending on the redox environment on cell surfaces and bacterial extracellular polymer coatings (Ghiorse, 1984). Thus, the presence of a biofilm might be expected to influence the subsequent deposition of colloidal oxides, such as iron oxyhydroxide, and in so doing could be expected to indirectly affect toxic transition metal distribution.

Mechanisms of particle deposition in biofilm systems have been discussed by Bouwer (1987). The deposition of iron oxyhydroxide onto a biofilm has been modeled in a manner comparable to removal of colloids in filtration processes (Sprouse and Rittmann, 1990a, b). This approach suggests that the 
particle size distribution of iron oxyhydroxide particles should influence transport to the surface. However, analysis of the iron particle size distribution is complicated if other colloidal sized particles, such as bacterial cells, are present in the suspension. Thus, the investigation of interactions between trace metals and both $\mathrm{Fe}$ oxides and bacterial cells requires the development of a protocol for determining the size distribution of suspended iron oxyhydroxide colloids in the presence of suspended cells. This paper reports the development of a protocol that uses a Coulter Multisizer ${ }^{\bar{R}}$ to measure size distributions of mixtures of colloidal $\mathrm{Fe}$ (III) and suspended cells before and after dissolution of the Fe(III). Several reagents were evaluated for their ability to dissolve $\mathrm{Fe}($ III) without altering the measured size distribution of suspended cells. Previous researchers have used organic chelators such as ethylenediaminetetracetate (EDTA) (Davies, 1970), oxalic acid (Ramsay et al., 1988) and ascorbic acid (Anderson and Morel, 1982) to dissolve colloidal iron, and these methods were evaluated in the present work. An inorganic reductant consisting of titanium(III) complexed by citrate and EDTA was found by Hudson and Morel (1989) to dissolve extracellular iron without causing cell breakage or toxicity for two marine phytoplankton. This method appeared promising for the present application and was investigated and adapted for use in this research.

The applicability of this new method for determining $\mathrm{Fe}$ (III) size distribution in the presence of suspended cells was demonstrated by the study of iron particle deposition to glass surfaces with and without adherent bacteria present. These experiments were conducted under controlled laboratory conditions in a biofilm reactor that contained a pure culture of bacteria in suspension and as a biofilm on glass slides. This biofilm reactor system was originally developed for modeling the interactions of toxic trace metals with a defined biofilm and planktonic biological component (Hsieh et al., 1985, 1994a, b; Nelson et al., 1995). Although not designed specifically for the study of iron oxide deposition, use of iron in the biofilm reactor experiments required an understanding of iron colloid deposition rates. This analysis provided an opportunity for application of the method for determining colloidal iron size distributions in the presence of suspended cells.

\section{MATERIALS AND METHODS}

\section{Preparation of colloidal iron oxyhydroxide}

Our choice of method for the preparation of colloidal iron oxyhydroxide was governed by the requirement that the resulting suspension have a stable particle size distribution, a suitable range of particle sizes, and a size distribution that was not altered by autoclaving. Addition of base to solutions of iron(III) salts has previously been used to prepare amorphous iron oxyhydroxide (Matijevic and Scheiner, 1978), a common component of natural aquatic systems that occurs both as a discrete mineral phase and as a surface coating on particulate matter (Jenne, 1968). This method was modified and found to fit our criteria. Since the chemical and structural composition, particle size, morphology, color and surface properties of the final product of the preparation process depend on the iron(III) concentration, $\mathrm{pH}$, temperature, ionic strength and the ionic composition of the solution (Matijevic and Scheiner, 1978), experimental conditions were carefully controlled to prepare iron colloids with a reproducible particle size distribution as described below.

Colloidal iron oxyhydroxide was prepared by addition of $\mathrm{NaOH}$ to acidified solutions of $\mathrm{Fe}\left(\mathrm{NO}_{3}\right)_{3}$ at $25^{\circ} \mathrm{C}$. Iron(III) nitrate solution $(0.1 \mathrm{M})$ was prepared in $0.15 \mathrm{M}$ dilute nitric acid. Sodium hydroxide $(3.0 \mathrm{M})$ was then added drop-wise to the acidified stock iron(III) solution until a $\mathrm{pH}$ of 8.0 was attained. The resulting suspension was aged for four weeks while the $\mathrm{pH}$ was monitored and maintained at $8.0 \pm 0.5$. Samples of $10 \mu \mathrm{l}$ each were periodically withdrawn from the suspension to evaluate the particle size distribution, as described below.

\section{Measurement of particle size distribution}

Particle sizes of both colloidal iron and bacterial cells were measured using a Coulter Multisizer II (Coulter Electric Limited, Luton, Beds., England). Samples were diluted with an electrolyte solution containing $0.9 \% \mathrm{NaCl}$ (Isoton II, Coulter Diagnostics, Hialeah, FL) to provide conductivity and to achieve a measurable particle concentration. A $50 \mu 1$ sample size was used for analysis with a $30 \mu \mathrm{m}$ aperture at an aperture current of $1300 \mu \mathrm{A}$. The Coulter Multisizer was interfaced with a Macintosh computer and a Hypercard ${ }^{\mathfrak{f}}$ program was used for data acquisition and calculation of particle size distribution.

The stability of dispersions of the iron colloids in the electrolyte solution used for size distribution analysis was checked by monitoring the particle size distribution after dilution. Counts and size distributions were similar $1 \mathrm{~min}$ and $30 \mathrm{~min}$ after mixing, indicating that the dispersion was stable in the counting solution for a much longer period than actually required for determination of the size distribution.

Measurement of iron colloid size distribution with bacterial cells present

The size distributions of colloidal iron in mixtures with bacterial cells were determined by measuring size distribution before and after dissolution of $\mathrm{Fe}$ (III) colloids. Several methods were evaluated for this purpose using methods based on EDTA, oxalic acid or titanium(III) treatments. EDTA was used at a concentration of $0.05 \mathrm{M}$ in an attempt to remove Fe(III) by chelation, using methods reported by Davies (1970), and oxalic acid was investigated for the same purpose using a method reported by Ramsay et al. (1988).

Use of a titanium reductant was then evaluated for its ability to dissolve $\mathrm{Fe}$ (III) without disrupting suspended bacterial cells. To a chelating solution containing $100 \mathrm{ml}$ of $0.05 \mathrm{M} \mathrm{Na} \mathrm{NaDTA}_{2}$ and $0.05 \mathrm{M}$ sodium citrate, $3.2 \mathrm{ml}$ of $20 \% \mathrm{TiCl}_{2}$ was added while stirring. The Ti(III) reagent was then titrated to $\mathrm{pH} 6$ by drop-wise addition of $10 \mathrm{M} \mathrm{NaOH}$. After the Ti(III) reagent was equilibrated for $30-60$ minutes, the $\mathrm{pH}$ was rechecked. Since oxygen will oxidize the reagent, glass-stoppered bottles with minimal headspace were used to store the reagent and fresh Ti(III) was prepared for each analysis.

\section{Bioreactor system}

The bioreactor system used for studying bacterial attachment and colloidal iron deposition under well-defined physical and chemical conditions has been described previously by Hsieh et al. (1985). A schematic diagram of the bioreactor system and the associated instrumentation is shown in Fig. 1. The bioreactor simulates an aquatic system where a defined surface area is in contact with a fluid flowing 


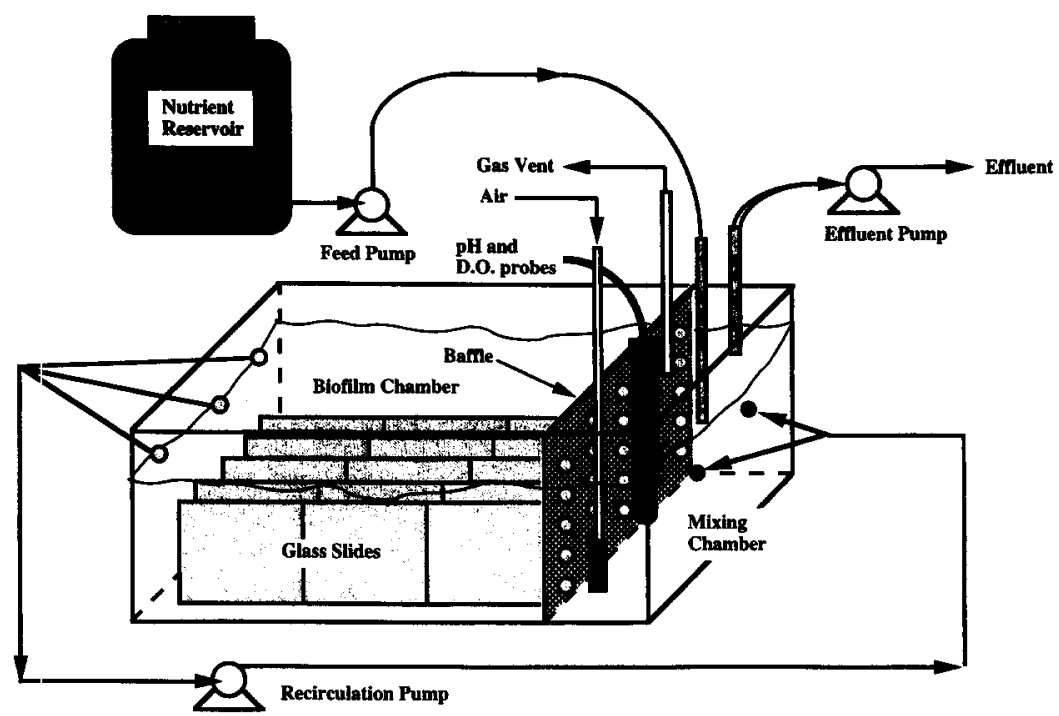

Fig. 1. Schematic diagram of biofilm reactor (from Hsieh et al., 1994a).

at a known velocity. The body of the bioreactor is constructed of high-density polyethylene with no metal parts in contact with the reactor fluid. The bioreactor consists of a mixing chamber and a biofilm chamber. The mixing chamber allow's for medium addition, acid and base additions, a $\mathrm{pH}$ probe, thermometer and aeration. The biofilm chamber contains 15 parallel lines of glass microscope slides to provide surfaces for cell attachment and colloidal iron deposition. Separate pumps were used for fluid recirculation in the reactor and for medium addition so that the fluid shear at the glass surfaces could be controlled independently of the mean reactor hydraulic residence time. The recirculation rate of $81 / \mathrm{min}$ resulted in a Reynold's Number of 320 .

The bioreactor system was operated within a laminar-flow hood to reduce the risk of microbial contamination. The possible presence of microbial contaminants was monitored during the course of bioreactor operation by plating fluid samples on peptone-trypticase-yeast-glucose (PTYG) agar plates (Murgel et al., 1991).

Prior to each experimental run, the glass slides were first cleaned with concentrated sulfuric acid mixed with Nochromix ${ }^{\mathbb{E}}$ cleaning solution (Godax Lab., Pawling, NY) which contains a chromate-free inorganic oxidizer. The bioreactor with slides; was acid cleaned with dilute $(10 \%)$ nitric acid for $12 \mathrm{~h}$, rinsed with distilled-deionized water and then cleaned with double-distilled nitric acid $(10 \%)$ for another $12 \mathrm{~h}$, followed by rinsing with sterilized distilleddeionized water. After this treatment, the reactor was sterilized with $70 \%$ ethanol at $\mathrm{pH} 2$ (by $\mathrm{HNO}_{3}$ addition) for $24 \mathrm{~h}$, then rinsed (five: times) with sterilized distilled-deionized water.

\section{Bacterial strain and culture medium}

A pure bacterial culture was used to avoid uncertainties that could arise from using undefined natural assemblages in which biofilm structure can change with changing environmental conditions. Burkholdaria cepacia 17616 (formerly Pseudomonas cepacia; Buchanan and Gibbons, 1984), a gram-negative obligate aerobic bacterium was supplied by T. Lessie, University Massachusetts, Amherst. This strain of B. cepacia has been found to grow as a biofilm on glass surfaces in a nutrient-limited MMS (minimal mineral salts)-based media that permits determination of the chemical speciation of trace metals (Murgel et al., 1991). When growing in suspension in MMS2 medium at $\mathrm{pH} 6.0$ (Table 1), the cells are rod-shaped, $0.6-1.0 \mu \mathrm{m}$ in diameter and $1.6-3.2 \mu \mathrm{m}$ in length. Cultures were maintained and stored at $4^{\circ} \mathrm{C}$ on plates containing PTYG agar medium.
Cultures for experimental use were transferred to $250 \mathrm{ml}$ shake flasks containing the MMS2 medium, and grown for approximately $36 \mathrm{~h}$ at $25^{\circ} \mathrm{C}$ on a rotary shaker at $200 \mathrm{rpm}$. To initiate an experiment, $100 \mathrm{ml}$ was subsequently used to inoculate the bioreactor (see below).

MMS2 medium was based on the MMS medium composition described by Murgel et al. (1991), and modified by increasing the phosphate concentration from $1.0 \mu \mathrm{M}$ to $5.0 \mu \mathrm{M}$ to avoid a phosphate-limitation on cell growth. Calculations performed using MINEQL (Westall et al., 1976) showed that the MMS2 medium at $\mathrm{pH} 6.0$ would not produce precipitates that would interfere with particle counting or affect trace metal adsorption in subsequent experiments. Pyruvate was chosen as the carbon and energy source. Filter sterilized $(0.22 \mu \mathrm{m}$ Millipore membrane, Bedford, MA) pyruvate was added to an autoclaved solution of the other medium components. Experimental pH was maintained at $6.0 \pm 0.1$ using a pH controller (Chemcadet, Cole Parmer, Niles, IL) to regulate addition of $0.02 \mathrm{M}$ solutions of $\mathrm{NaOH}$ and $\mathrm{HNO}_{3}$.

\section{Enumeration of bacterial cells}

Suspended bacterial cells were enumerated using a Coulter Multisizer II, as described above. Before counting, cells were fixed by adding a $25 \%$ solution of glutaraldehyde to samples to attain a final glutaraldehyde concentration of $0.25 \%$. After $10 \mathrm{~min}$ fixation, $100 \mu 1$ aliquots of the sample were added to $20 \mathrm{ml}$ of an isotonic solution (Isoton II, Coulter Diagnostics, Hialeah, FL) for counting.

Glass slides removed from the bioreactor were examined for bacterial cell attachment and extracellular polymer formation by both direct microscopic counts of attached cells and chemical oxygen demand (COD) analysis. The number of attached cells on the glass slide per unit surface area was directly enumerated using a Zeiss Universal light microscope equipped with phase-contrast optics and a calibrated reticule. A magnification of $1260 \times$ was used for

Table 1. Composition of MMS-2 medium

\begin{tabular}{lc}
\hline Component & Concentration (M) \\
\hline $\mathrm{CaCl}_{2} \cdot 2 \mathrm{H}_{2} \mathrm{O}$ & $2.04 \times 10^{-4}$ \\
$\mathrm{MgSO}_{4} \cdot 7 \mathrm{H}_{2} \mathrm{O}$ & $1.40 \times 10^{-4}$ \\
$\left(\mathrm{NH}_{4}\right)_{2} \mathrm{SO}_{4}$ & $9.08 \times 10^{-4}$ \\
$\mathrm{KNO}_{3}$ & $1.46 \times 10^{-4}$ \\
$\mathrm{NaHCO}_{3}$ & $1.00 \times 10^{-5}$ \\
$\mathrm{KH}_{2} \mathrm{PO}_{4}$ & $5.00 \times 10^{-6}$ \\
Pyruvate & $9.09 \times 10^{-4}$ \\
\hline
\end{tabular}

Sodium nitrate added to adjust ionic strength to $0.05 \mathrm{M}, \mathrm{pH}$ adjusted to 6.0 . 
cell enumeration. The COD of the biofilms was determined using a standard dichromate reflux method for low COD concentrations (Standard Methods, 1989). Glass slides removed from the bioreactor were rinsed briefly in deionized water to remove residual medium and suspended cells and allowed to air dry. The slides were broken, placed into $250 \mathrm{ml}$ Erlenmeyer flasks and subjected to the COD procedure. COD results are expressed in units of milli-equivalents (meq), which is equivalent to the number of millimoles of electrons transferred during oxidation.

\section{Chemical analyses}

Deposited iron on slides was also measured spectroscopically for a direct measurement of Fe accumulation and to determine the relative amounts of $\mathrm{Fe}$ deposited onto glass slides versus other wetted reactor surfaces. Deposited $\mathrm{Fe}$ was removed from slides by extraction with $15 \% \mathrm{HNO}_{3} . \mathrm{Fe}$ concentrations in the extract were measured by graphite furnace atomic absorption spectrophotometry (GFAAS) using a Model 460 atomic absorption spectrophotometer equipped with a Model HGA-2100 graphite furnace (Perkin-Elmer, Norwalk, CT).

Pyruvate concentration in the reactor was determined using the Sigma Pyruvate Diagnostic Kit (Sigma Chemical Co., St. Louis, MO). A $2.0 \mathrm{ml}$ volume of diluted sample, $0.5 \mathrm{ml}$ of TRIZMA base solution and $0.5 \mathrm{ml}$ NADH solution were added to a $1 \mathrm{~cm}$ light path curve. After reading the absorbance of the solution at $340 \mathrm{~nm}$ with a spectrophotometer (Model 3600, Beckman Instruments, Inc., Irvine, CA), $0.05 \mathrm{ml}$ lactate dehydrogenase was added to catalyze the conversion of pyruvate to lactate. After approximately $2-5 \mathrm{~min}$, the absorbance at $340 \mathrm{~nm}$ was used to assay the residual concentration of NADH. Pyruvate concentration was calculated by using a standard calibration curve (Sigma Diagnostic, 1990).

\section{RESULTS}

\section{Colloidal iron oxyhydroxide stability}

During initial aging, the iron(III) oxyhydroxide colloids aggregated to form larger particles (Fig. 2). The aggregation of small Fe colloids was most rapid over the first several days of aging. Comparison of the size distributions at 19.0 days and 28.1 days indicated that the colloids were relatively stable after 19 days. In the aged suspension, the rate of aggregation of smaller particles was very slow compared to the deposition rates being measured over the duration of experiments in the bioreactor (described below). The observed particle size distribution indicated that particles smaller than $0.75 \mu \mathrm{m}$ probably exhibited the highest maximum number concentration (Fig. 2).

Colloid stability in the MMS2 medium was evaluated by spiking the medium with stock colloidal Fe suspensions that had been aged for 4 weeks. Samples were withdrawn periodically for determination of particle size distribution using a Coulter Multisizer. Under these conditions, the iron(III) colloids were stable with respect to aggregation (Fig. 3). The effect of autoclaving the iron suspension was also investigated since additions to the reactor were autoclaved to maintain sterile conditions during bioreactor operation. After 23 days of aging, the size distribution of autoclaved colloids was similar to that of iron colloids that were not autoclaved (Fig. 4). Although slightly more aggregation occurred in the iron suspension that had not been autoclaved than in the autoclaved sample, the autoclaved iron suspension was still considered suitable for study of iron deposition. Autoclaving of iron colloids that had been aged for 4 weeks was also found to have no significant effect on the size distribution.

\section{Determination of iron(III) colloid size distribution in the presence of suspended cells}

To examine colloidal iron size distribution in the presence of suspended cells, an experimental protocol was developed to distinguish the size distribution of iron colloids from that of cells. The goal was to dissolve iron colloids without affecting suspended

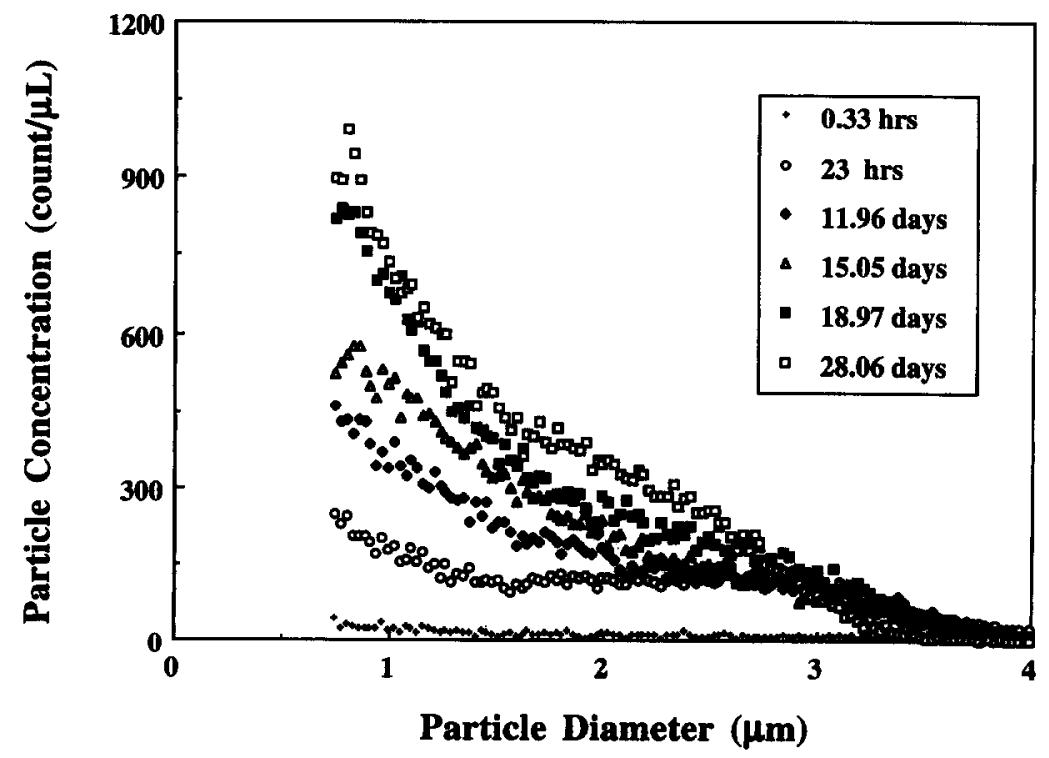

Fig. 2. Preparation of a stable colloidal iron oxide solution. 


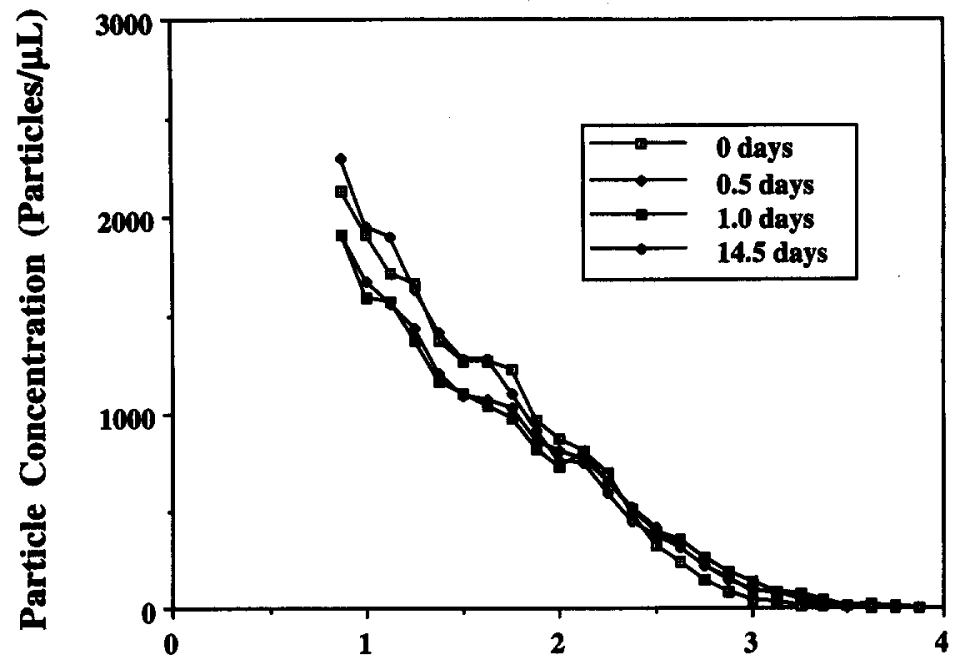

Particle Diameter $(\mu \mathrm{m})$

Fig. 3. Stability of colloidal iron oxide in the MMS-2 growth medium.

cells and then determine iron colloid size distribution from the difference between measured size distributions before and after $\mathrm{Fe}$ dissolution. Attempts to use EDTA or oxalic acid for this purpose were unsuccessful. EDTA $(0.05 \mathrm{M})$ was found to be ineffective in dissolving iron colloids, and additions of $5 \%(\mathrm{wt} / \mathrm{vol})$ oxalic acid were found to change the size distribution of suspended B. cepacia cells significantly. Centrifugation was also investigated, but it failed to separate iron colloids and bacterial cells.

Use of the Ti(III) reductant to dissolve Fe(III) was more successful. The Ti(III) reagent was first tested in the absence of suspended cells. Aged $\mathrm{Fe}$ (III) oxyhydroxide $(10 \mathrm{mg} / \mathrm{l})$ was completely dissolved by Ti(III) reagent within $5 \mathrm{~min}$ of exposure to the reagent. In tests with a cell suspension, the size distribution of $B$. cepacia cells did not change significantly after exposure to the Ti(III) reagent. The Ti reduction method was then tested using mixed suspensions of $\mathrm{Fe}$ (III) and $B$. cepacia cells. Iron colloids with a predetermined size distribution were mixed with a suspension of $B$. cepacia sampled from the bioreactor to make up a $10 \mathrm{mg} / \mathrm{l}$ colloidal iron suspension. Samples withdrawn from the mixture were then analyzed with the Coulter Multisizer II. The resulting size distribution gave the sum of the particle size distributions of both suspended cells and iron colloids. Titanium(III) reagent was then added to the suspension at a reagent to suspension volume ratio of 4:1 to dissolve the iron colloids in the mixture. After $15 \mathrm{~min}$ of reaction time, the size

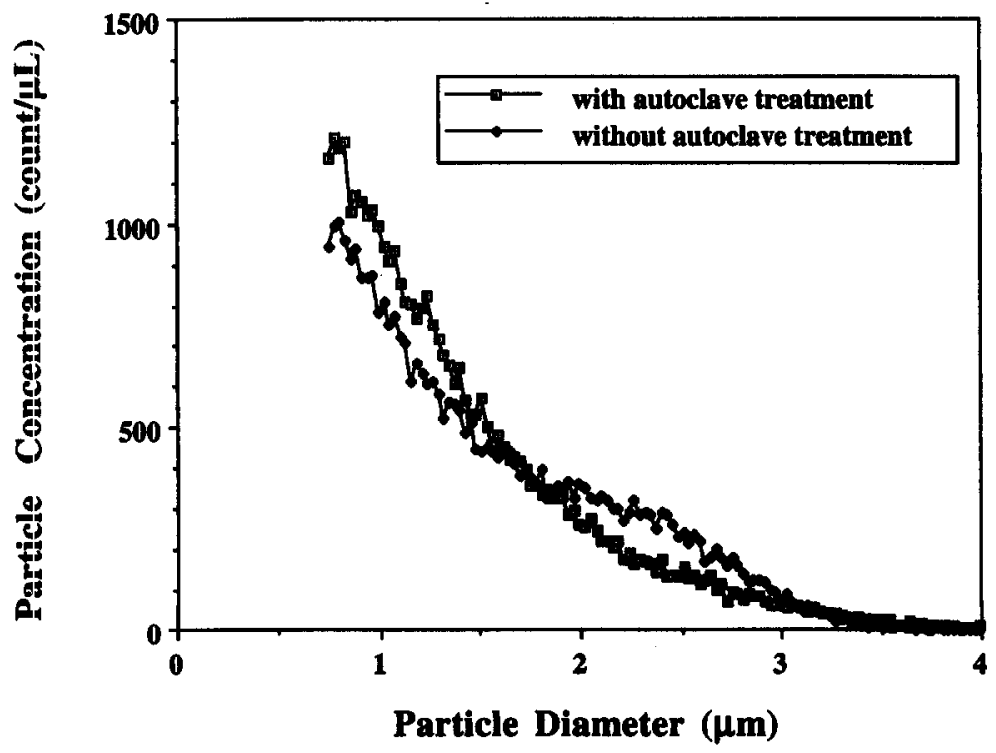

Fig. 4. Particle size distribution of colloidal iron oxide after 23 days of aging with autoclave treatment at $7 \mathrm{~h}$ of aging compared to the particle size distribution of colloidal iron oxide after 23 days of aging without autoclave treatment. 


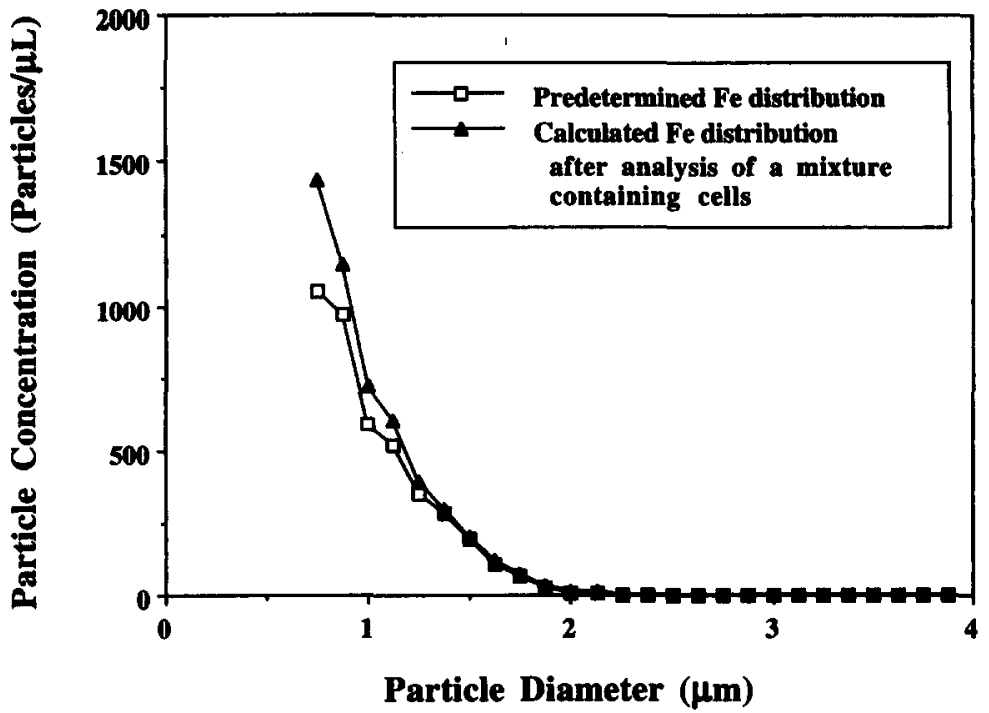

Fig. 5. Predetermined size distribution of colloidal iron oxide compared to the experimentally determined size distribution of colloidal iron oxide using the titanium(III) reagent.

distribution was again determined to give the size distribution of suspended cells only. The size distribution of colloidal iron was calculated by subtracting the size distribution of suspended cells after removal of iron from the size distribution of suspended cells in the presence of colloidal iron. The experimentally determined size distribution of colloidal iron is compared to the predetermined size distribution in Fig. 5. The two distributions are in good agreement, especially considering experimental variability of the particle size analyses. Thus, this protocol can be applied for determining the size distribution of iron colloids in the presence of suspended cells.

\section{Colloidal iron deposition in the bioreactor: aseptic conditions}

To investigate colloidal iron deposition to reactor surfaces in the absence of suspended cells, a series of colloidal iron(III) additions were made to the bioreactor during aseptic, continuous-flow operation. Experimental operating conditions of the reactor system during these experiments are listed in Tables 1 and 2. Pulses of colloidal iron(III) were added at $24 \mathrm{~h}$ intervals for 7 days. Each pulse corresponded to an added concentration of $10 \mathrm{mg} / \mathrm{l}$ iron. After each pulse addition, samples were withdrawn at regular intervals from the bioreactor for determination of particle size distribution using the Coulter Multisizer II. The total particle concentration of the bulk liquid phase of the bioreactor is shown versus time in Fig. 6. The figure shows that colloidal iron was rapidly removed from the bulk liquid phase and presumably deposited onto the glass slides and other wetted reactor surfaces following introduction of the iron pulses. Only a low concentration (15\% of initial) of colloidal iron was found in the bulk liquid phase $12 \mathrm{~h}$ after the introduction of each pulse. In comparison, about $70 \%$ of the added iron would be expected to remain after $12 \mathrm{~h}$ if iron colloids were lost to washout alone, assuming continuous-flow-stirred tank behavior. The deposition rate of iron did not appear to be affected by the deposition of iron from prior pulse additions.

Iron deposition rates were strongly affected by particle size. The particle size distribution of iron in the bulk solution phase at different elapsed times after the first pulse addition is shown in Fig. 7. Under these conditions, larger colloids were deposited to the sum of all reactor surfaces faster than small particles. To further evaluate the kinetics of $\mathrm{Fe}$ colloid deposition, deposition rate constants were calculated by assuming a first-order dependence on concentration. With this assumption, a plot of the logarithm of the iron particle concentration versus time would yield a straight line with a slope of $\left.-\left[\left(F / V_{\mathrm{R}}\right)+k\right)\right]$, where $F$ is the feed flow rate, $V_{\mathrm{R}}$ is the total reactor volume, and $k$ is the first-order kinetic rate constant for particle deposition. As an example, Fig. 8 shows such a plot for particles in the $0.75-0.875 \mu \mathrm{m}$ size range. The linearity of this and similar plots for other particle diameters indicates that a first-order model for particle removal was a reasonable approximation. First-order deposition rate constants obtained from these plots are listed for five deposition experiments in Table 3A. These results confirm an increase in deposition rate constant with increasing particle size.

Table 2. Biofilm reactor operating conditions

\begin{tabular}{ll}
\hline Temperature & $25^{\circ} \mathrm{C}$ \\
pH & 6.0 \\
Total reactor liquid volume & $1.2 \mathrm{I}$ \\
Medium feed rate & $11 /$ day \\
Hydraulic retention time & $29 \mathrm{~h}$ \\
Carbon source & $0.1 \mathrm{~g} / 1$ pyruvate \\
Medium & $\mathrm{MMS} 2$ \\
Ionic strength & $0.05 \mathrm{M}$ \\
Recirculation rate & $81 / \mathrm{min}(\mathrm{Re}=320)$ \\
Air flow rate & $0.5 \mathrm{SCFH}$ \\
\hline
\end{tabular}




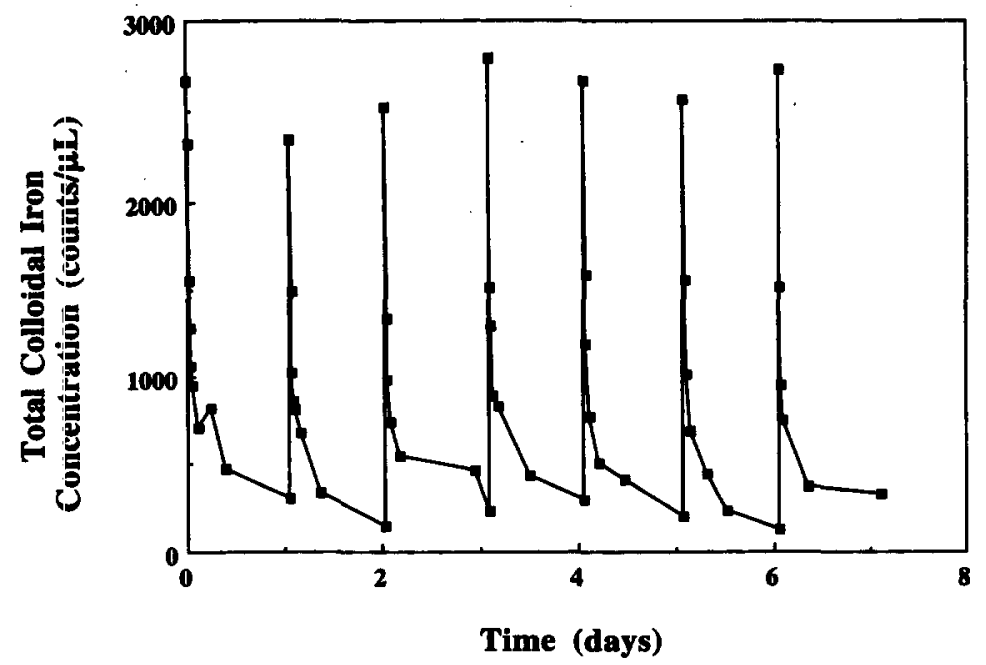

Fig. 6. Deposition of pulse inputs of colloidal iron oxide in the biofilm reactor during aseptic operation.

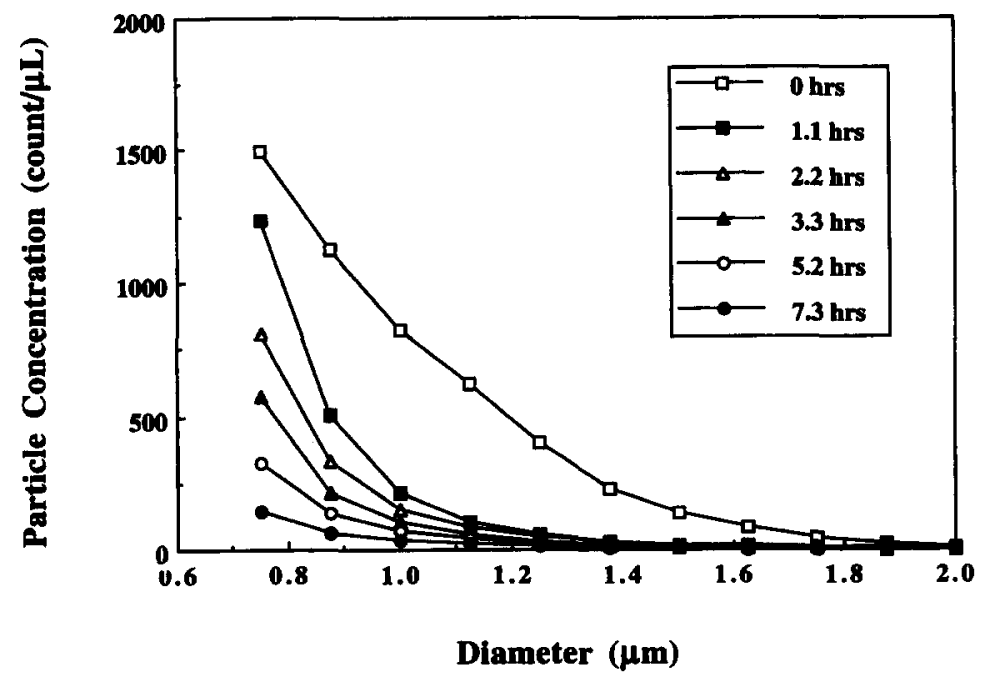

Fig. 7. Particle concentration of colloidal iron oxide at different elapsed times in the biofilm reactor as a function of particle size during aseptic operation.

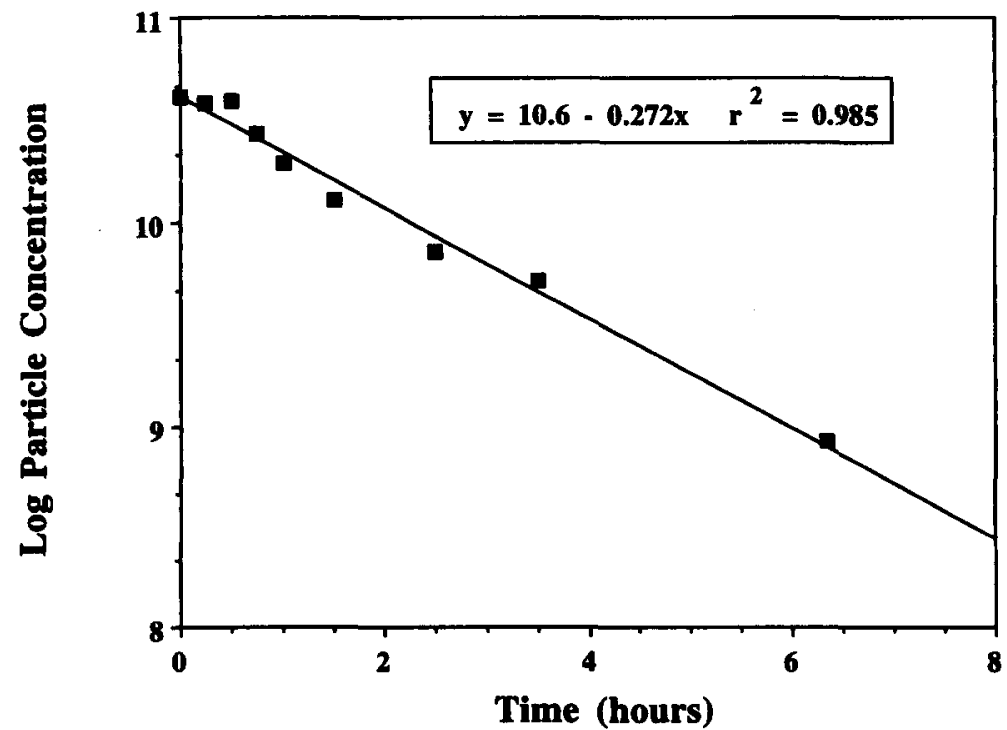

Fig. 8. Deposition of colloidal iron oxide $(0.75-0.88 \mu \mathrm{m}$ size range) onto inorganic surfaces in the absence of biofilm. The logarithm of the particle concentration is plotted versus time. 
Table 3A. First-order Fe deposition rate constants for five sequential additions of colloidal Fe to the biofilm reactor without biofilms present

\begin{tabular}{lccccccc}
\hline \multirow{2}{*}{$\begin{array}{l}\text { Size range } \\
(\text { diameter, } \mu \mathrm{m})\end{array}$} & 1st & 2nd & 3rd & 4th & 5th & Average & Std. Dev. \\
\cline { 2 - 8 } & 0.26 & 0.13 & 0.18 & 0.10 & 0.19 & 0.17 & 0.06 \\
$0.75-0.88$ & 0.32 & 0.14 & 0.20 & 0.12 & 0.21 & 0.20 & 0.08 \\
$0.88-1.25$ & 2.0 & 1.55 & 0.47 & 1.87 & 2.3 & 1.64 & 0.71 \\
$1.25-1.75$ & 5.11 & 6.49 & 4.92 & 4.79 & 10.0 & 6.26 & 2.20 \\
$1.75-1.88$ & 4.91 & 6.01 & 6.34 & 6.66 & 12.0 & 7.18 & 2.77 \\
$1.88+$ & & & & & & &
\end{tabular}

Colloidal iron deposition in the bioreactor: with biofilms present

The protocol for determination of iron particle size distribution in the presence of cells was used for studying iron deposition onto biofilm-coated surfaces. For these experiments, the biofilm reactor with glass slides was inoculated with $B$. cepacia and operated as described above (Tables 1 and 2). The bioreactor was operated in batch mode for the first $40 \mathrm{~h}$, then in continuous-flow mode with a hydraulic residence time of $28.6 \mathrm{~h}$ for the rest of the experiment. The purpose of the batch period was to allow the initial population of cells to increase without washing them out of the reactor. Figure 9 shows the suspended cell counts and pyruvate concentrations over the time course of the experiment. Pyruvate concentration in the bioreactor decreased rapidly from $100 \mathrm{mg} / \mathrm{l}$ to about $2-5 \mathrm{mg} / \mathrm{l}$ after approximately 1.5 days (Fig. 9). Beginning on the 25th day of operation, several pulses of colloidal iron were introduced into the bioreactor. Each pulse addition constituted a bulk iron concentration of $10 \mathrm{mg} / \mathrm{l}$. After each iron pulse was introduced, samples were withdrawn to determine the size distribution of colloidal iron using the experimental protocol described above.

Attached cell concentrations and the COD of adherent biomass were determined for glass slides removed from the bioreactor just prior to the introduction of iron. The attached cell population density was $2.2 \pm 0.3 \times 10^{5}$ cells $/ \mathrm{mm}^{2}$ which corresponded to approximately $20 \%$ surface coverage. The COD of attached cells was $23 \mathrm{meq}$ $\mathrm{COD} / \mathrm{m}^{2}$.

As observed under aseptic conditions, most of the colloidal iron in a pulse addition was removed from the suspension after $6 \mathrm{~h}$. The colloidal iron particle concentration at different elapsed times is plotted versus particle size in Fig. 10. Comparison of Figs 7 and 10 shows that similar trends in deposition rate with particle size were observed under both aseptic and inoculated conditions. First-order deposition rate constants for iron deposition onto the biofilm-coated surfaces were calculated as above (Table 3B), and compared to the rate constants determined in the absence of biofilm (Table 3A). With $20 \%$ biofilm surface coverage on the glass slides, the presence of biofilms appears to have resulted in faster deposition of small particles and slower deposition of larger particles. However, these trends were not significant given the level of experimental variance. The effect of the biofilm on deposition of colloidal iron particles smaller than the $0.70 \mu \mathrm{m}$ detection limit of the Coulter Multisizer II could not be observed.

The effect of biofilm coverage on Fe deposition to glass reactor slides was further investigated using direct GFAAS measurement of Fe extracted from

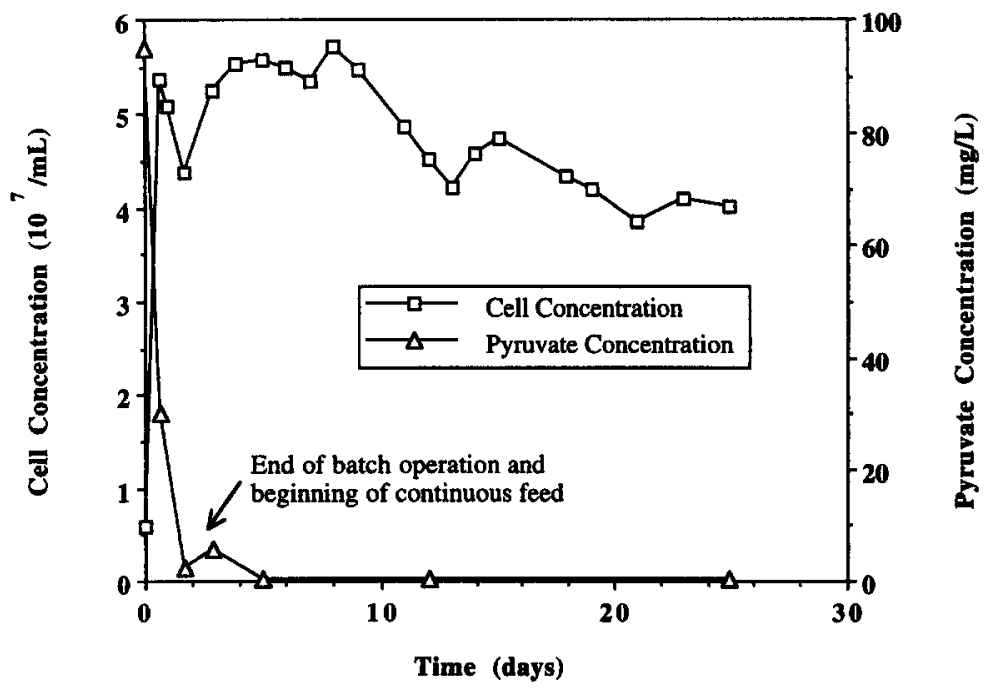

Fig. 9. Time-course experimental data during operation of the biofilm reactor. Batch operation for the first $40 \mathrm{~h}$. Continuous operation after the first $40 \mathrm{~h}$. 
Table 3B. First-order Fe deposition rate constants for five sequential additions of colloidal Fe to the biofilm reactor with biofilms present

\begin{tabular}{lccccccc}
\hline & \multicolumn{7}{c}{ Deposition rate constant } \\
\cline { 2 - 8 } $\begin{array}{l}\text { Size range } \\
\text { (diameter, } \mu \mathrm{m} \text { ) }\end{array}$ & 1 st & 2nd & 3rd & 4th & 5th & Average & Std. Dev. \\
\hline $0.75-0.88$ & 0.26 & 0.17 & 0.56 & 0.44 & 0.38 & 0.36 & 0.15 \\
$0.88-1.25$ & 0.39 & 0.20 & 1.06 & 0.57 & 0.40 & 0.52 & 0.33 \\
$1.25-1.75$ & 1.17 & 1.63 & 2.07 & 1.75 & 1.55 & 1.63 & 0.33 \\
$1.75-1.88$ & 2.49 & 4.21 & 6.71 & 5.80 & 5.36 & 4.91 & 1.63 \\
$1.88+$ & 2.02 & 4.05 & 8.20 & 5.24 & 5.54 & 5.01 & 2.26 \\
\hline
\end{tabular}

biofilm surface coatings. After pulse additions of colloidal iron, average deposited $\mathrm{Fe}$ concentrations . were $73 \pm 34 \mu \mathrm{mol} / \mathrm{m}^{2}$ in the absence of biofilms and increased to $125 \pm 63 \mu \mathrm{mol} / \mathrm{m}^{2}$ in the presence of $B$. cepacia biofilms (significantly different at the $95 \%$ confidence interval).

\section{Fe deposition to different reactor system surfaces}

The biofilm reactor system has many wetted surfaces other than the glass slides available for iron deposition. These surfaces include reactor walls and surfaces within the recirculation pump and tubing. A mass balance of iron colloids was performed to determine the distribution of deposited iron throughout the reactor system. Glass slides were withdrawn and submerged for several days in $20 \mathrm{ml} 15 \%$ nitric acid to extract the iron colloids deposited on the glass slides at the end of a deposition experiment. With the glass slides removed, dilute nitric acid was added to the reactor to extract the iron deposited on wetted surfaces other than glass surfaces. Of the total iron deposited, $31 \%$ was associated with the glass slides and $69 \%$ with the other wetted surfaces.

\section{DISCUSSION}

The Ti(III) reductant method for determining particle size distributions of Fe(III) colloids in the presence of bacterial cells was successful and straightforward, while the results of the Fe deposition experiments in the bioreactor warrant some discussion relative to the processes governing colloid transport and deposition. The deposition of colloidal particles from flowing suspensions onto stationary surfaces can be conceptually divided into two sequential steps: transport and attachment. Transport of colloidal particles from the bulk of suspensions to the vicinity of a stationary surface is governed mainly by Brownian diffusion, interception and sedimentation. Particle attachment, on the other hand, is dominated by the interaction forces between the suspended colloidal particles and the stationary surfaces at short distances (several to a few tens of nanometers) (Elimelech and O'Melia, 1990). These interaction forces are the sum of van der Vaals and electric double-layer interactions according to the Derjaguin-Landau-Verwey-Overbeek (DLVO) theory of colloidal stability (Derjaguin and Landau, 1941; Verwey and Overbeek, 1948).

In the biofilm reactor, 15 parallel lines of glass slides provided the stationary surface for cell attachment and colloidal iron deposition. The system can be idealized as an aqueous suspension of iron colloids and bacterial cells undergoing laminar flow $(\operatorname{Re}=320)$ through a channel consisting of two flat plates onto which the iron colloids may deposit.

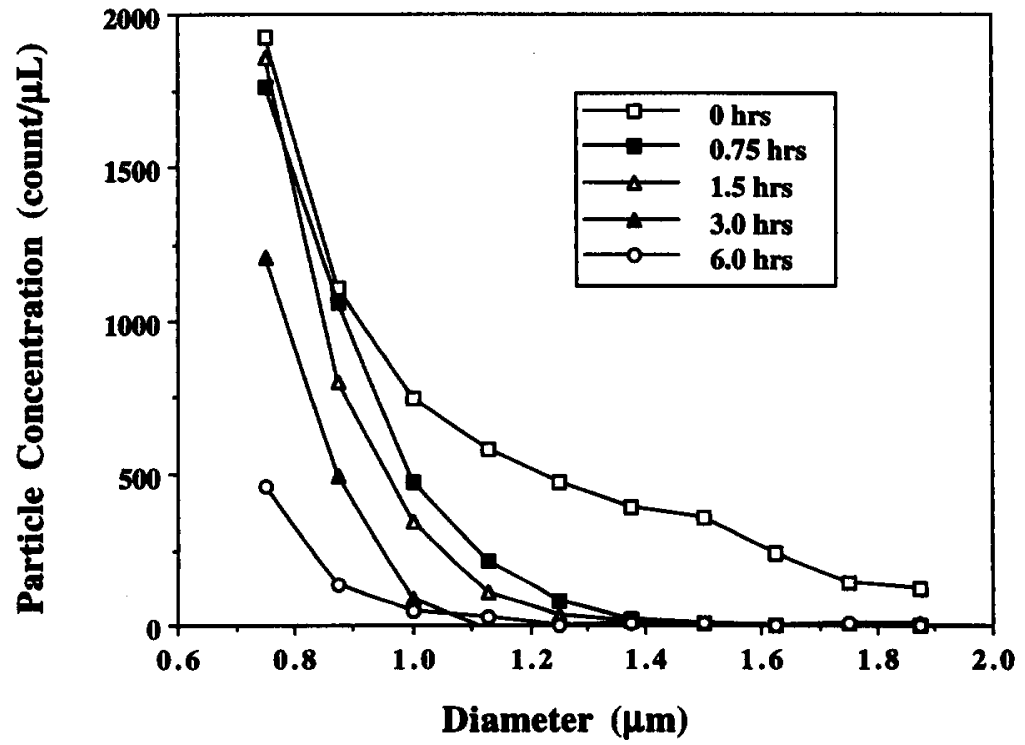

Fig. 10. Particle concentration of colloidal iron oxide at different elapsed times in the biofilm reactor as a function of particle size during continuous operation. 
Under these idealized conditions, Brownian diffusion would be expected to dominate colloid transport, while interception and sedimentation would be insignificant. However, in the biofilm reactor experiments, $\mathrm{Fe}$ deposition rates increased with increasing particle size, which would be expected if interception and/or sedimentation dominated transport. Flow from the reactor recirculation system mixing zone and at junctions between the rows of slides may have introduced enough turbulence to facilitate interception in addition to Brownian transport under the conditions of these experiments. In addition, significant amounts of iron deposited on wetted reactor surfaces other than the glass slides, accounting for about $70 \%$ of the total iron deposited in the reactor system. Therefore, deposition rates determined in this work were the composite of deposition to glass surfaces and to other wetted reactor surfaces. Mechanisms of transport to these other reactor surfaces (such as fluid recycle lines which included $90^{\circ}$ bends) could be largely controlled by interception. Deposition to the slides alone could be estimated by measuring $\mathrm{Fe}$ deposition in the reactor with the glass slides removed and subtracting the observed deposition rates from those observed with slides present. Preliminary experiments of this nature indicated that when deposition to other reactor surfaces was subtracted, deposition rates to the glass surfaces actually increased with decreasing particle size. This observation is in keeping with that expected for diffusion-dominated transport. However, because of the experimental error associated with the measurements of deposition rates in the biofilm reactor, it was difficult to obtain statistical significance when subtracting the rate data for conditions with and without slides.

Particle attachment in the bioreactor is expected to be governed by both the van der Waals and electric double-layer interaction forces between the suspended colloidal iron particles and the biofilm-coated glass surface. For the deposition of the positively charged iron colloids $\left(\mathrm{pH}_{\mathrm{Pzc}}=7.9\right.$; Davis and Leckie, 1978b) onto a negatively charged glass surface, the interaction forces are attractive and the attachment efficiency would be close to one. When bacterial cells with secreted extracellular polymer are attached to surfaces, the interaction potential between the suspended iron colloids and the stationary surface could be changed. However, bacterial cells generally exhibit negative surface charges (Gannon et al., 1991), with isoelectric points between $\mathrm{pH} 2$ and 4 (Beveridge, 1981). Also, the experimental cell surface coverage was only $20 \%$, and thus the attachment efficiency of colloidal iron particles would be anticipated to still be high (near 1). Experimentally, mixed results were obtained for the influence of biofilms on $\mathrm{Fe}$ deposition to glass surfaces. Comparison of observed iron deposition rates, as determined by measuring the disappearance of suspended particles, indicated that the presence of $B$. cepacia biofilms did not significantly influence iron colloid deposition under these conditions. In contrast, when measured using GFAAS analysis of surface coatings, the presence of attached cells increased $\mathrm{Fe}$ deposition rates. This discrepancy was probably caused by the influence of $\mathrm{Fe}$ deposition to reactor surfaces other than glass in the colloid enumeration experiments.

Previously deposited Fe(III) oxides might be expected to decrease the $\mathrm{Fe}$ deposition rate of subsequent $\mathrm{Fe}$ colloid additions by making the surface charge of the glass surface more positive, and therefore decreasing electrostatic attraction to the glass and biofilm. However, no such decrease in deposition rate was observed over the course of five sequential pulse additions of $\mathrm{Fe}$ (Tables $3 \mathrm{~A}$ and $\mathrm{B}$ ). This observation suggests that either electrostatic interactions did not significantly impact Fe deposition rates or that deposition to other reactor surfaces occluded observation of this effect. Deposits of multiple layers of $\mathrm{Fe}$ colloids were observed on the glass slides using confocal scanning laser microscopy, indicating the absence of excluded area effects which would be expected for deposition controlled by electrostatic interactions.

\section{CONCLUSIONS}

Titanium(III) reagent was successfully used as an inorganic reductant for determination of the size distribution of colloidal $\mathrm{Fe}(\mathrm{III})$ oxyhydroxide in the presence of suspended bacterial cells. The Ti(III) reagent dissolved $95 \%$ of $\mathrm{Fe}$ colloids and had no significant effect on the measured size distribution of suspended B. cepacia cells. Thus, Fe colloid size distributions in mixtures with suspended cells could be accurately determined from the difference in size distribution before and after dissolution of $\mathrm{Fe}$ colloids with $\mathrm{Ti}(\mathrm{III})$.

A limitation of this study was that the Coulter Counter instrument could not measure particles with diameters less than $0.7 \mu \mathrm{m}$. However, the protocol presented for measuring colloidal iron size distribution in the presence of cells is general and can be coupled with other techniques to determine size distributions (e.g. photon correlation spectroscopy) and thus remove this limitation.

The method of analysis of colloidal $\mathrm{Fe}$ in the presence of suspended bacterial cells was applied to the study of iron particle deposition to glass surfaces with and without adherent biofilms of a single bacterial strain. A laboratory-scale, bioreactor system with controlled physical and chemical conditions provided the test environment for this application. This bioreactor was developed for the study of the interactions of toxic transition metals with biofilms, and was not designed specifically for studying the influence of biofilms on iron deposition. Because of the high deposition rate of iron to surfaces other than the glass slides, the method of measuring iron deposition by disappearance from solution is not 
ideal for studying the influence of biofilms on iron deposition. However, use of this reactor system for modeling trace metal behavior in the presence of colloidal $\mathrm{Fe}$ necessitated the development of the protocol described here.

Experimental results show that the deposition rate of iron colloids in the reactor increased as colloidal particle size increased. The presence of a non-confluent biofilm of $B$. cepacia ( $20 \%$ surface coverage) did not significantly alter the deposition rate of colloidal iron when determined from the rate of disappearance of suspended Fe colloids. However, direct spectroscopic measurement of deposited $\mathrm{Fe}$ indicated that the presence of biofilm increased Fe deposition rates slightly. A greater influence of biofilms on Fe colloid deposition rate might be expected for biofilms with greater surface coverage and for surfaces on which attached bacteria exert more influence on the net overall surface charge.

Acknowledgements-This work was supported by the National Science Foundation, under Grant \# BCS-9100209. The authors are grateful for the technical assistance of Sharon Best and Rhea Garen in the Cornell University Section of Microbiology and Cameron Willkens in the School of Civil and Environmental Engineering. Dr Monroe Weber-Shirk developed the Hypercard ${ }^{\mathbb{E}}$ program used for analysis of Coulter Counter data and provided assistance with these analyses.

\section{REFERENCES}

Anderson M. A. and Morel F. M. M. (1982) The influence of aqueous iron chemistry on the uptake of iron by the coastal diatom Thalassiosira weissfogii. Limnol. Oceanogr. 27, 789-813.

function of the bacterial wall. Int. Rev. Cytol. 72, 229-317.

Bouwer E. J. (1987) Theoretical investigation of particle deposition in biofilm systems. Wat. Res. 21, 1489-1498.

Buchanan R. E. and Gibbons N. E. (Eds) (1984) Bergey's Manual of Systematic Bacteriology, Vol. I. William and Wilkens Co., Baltimore.

Davies A. G. (1970) Iron chelation and the growth of marine phytoplankton 1. Growth kinetics and chlorophyll production in cultures of euryhaline flagellate Dunaliella teriolecta under iron limiting conditions. $J$. Mar. Biol. Assoc. U.K. 50, 65-86.

Davis J. A. and Leckie J. O. (1978a) Effect of adsorbed complexing ligands on trace metal uptake by hydrous oxides. Environ. Sci. Technol. 12, 1309-1315.

Davis J. A. and Leckie J. O. (1978b) Surface ionization and complexation at the oxide/water interface. II. Surface properties of amorphous iron oxyhydroxide and adsorption of metal ions. J. Colloid Interface Sci. 67, 90-104.

Derjaguin B. V. and Landau L. D. (1941) Theory of the stability of strongly charged lyophobic sols and of the adhesion of strongly charged particles in solutions of electrolytes. Acta Physicochimica 14, 633.

Elimelech M. and O'Melia C. R. (1990) Kinetics of deposition of colloidal particles in porous media. Environ. Sci. Technol. 24, 1528-1536.

Gannon J. T., Manilal V. B. and Alexander M. (1991) Relationship between cell surface properties and transport of bacteria through soil. Appl. Environ. Microbiol. 57(1), 190-193.

Ghiorse W. C. (1984) Biology of iron- and manganesedepositing bacteria. Ann. Rev. Microbiol. 38, 515550.
Hsieh K. M., Lion L. W. and Shuler M. L. (1985) Bioreactor for the study of defined interactions of toxic trace metals and biofilms. Appl. Environ. Microbiol. 50(5), 1155-1161.

Hsieh K. M., Murgel G. A., Lion L. W. and Shuler M. L. (1994a) Interactions of microbial biofilms with toxic trace metals: 1. Observation and modelling of cell growth, attachment, and production of extracellular polymer. Biotechnol. Bioeng. 44, 219-231.

Hsieh K. M., Murgel G, A., Lion L. W. and Shuler M. L. (1994b). Interactions of microbial biofilms with toxic trace metals: 2. Prediction and verification of an integrated computer model of lead(II) distribution in the presence of microbial activity. Biotechnol. Bioeng. 44, 232-239.

Hudson R. J. M. and Morel F. M. M. (1989) Distinguishing between extra- and intracellular iron in marine phytoplankton. Limnol. Oceanogr. 34(6), 1113-1120.

Jenne E. A. (1968) Controls on $\mathrm{Mn}, \mathrm{Co}, \mathrm{Ni}, \mathrm{Cu}$ and $\mathrm{Zn}$ concentrations in soil and water: The significant role of hydrous $\mathrm{Mn}$ and $\mathrm{Fe}$ oxides. Trace Inorganics in Water. American Chemical Society, Washington, DC, pp. 337-387.

Kruaskopf K. B. (1956) Factors controlling the concentration of thirteen rare metals in seawater. Geochim. Cosmochim. Acta 9, 1-24.

Lion L. W., Altmann R. S. and Leckie J. O. (1982) Trace-metal adsorption characteristics of estuarine particulate matter: Evaluation of contributions of $\mathrm{Fe} / \mathrm{Mn}$ oxide and organic surface coatings. Environ. Sci. Technol. 16(10), 660-666.

Lion L. W., Shuler M. L., Hsieh K. M. and Ghiorse W. C. (1988) Trace metal interactions with microbial biofilms in natural and engineered systems. CRC Crit. Rev. Environ. Control 17(4), 273-306.

Matijevic E. and Scheiner P. (1978) Ferric hydrous oxide sols III. Preparation of uniform particles by hydrolysis of $\mathrm{Fe}(\mathrm{III})$-chloride, -nitrate, and -perchlorate solutions. $J$. Colloid Interface Sci. 63(3), 509-524.

Murgel G., Lion L. W., Acheson C., Shuler M. L., Emerson D. and Ghiorse W. C. (1991) An experimental apparatus for selection of adherent microorganisms under stringent conditions. Appl. Environ. Microbiol. 57(7), 1987-1996.

Nelson Y. M., Lo W., Lion L. W., Shuler M. L. and Ghiorse W. C. (1995) Lead distribution in a simulated aquatic environment: Effects of bacterial biofilms and iron oxide. Wat. Res. 29(8), 1934-1944.

Ramsay B., Ramsay J., Tremblay de M. and Chavarie C. (1988) A method for the quantification of bacterial protein in the presence of jarosite. Geomicrobiol. J. 6, 171-177.

Sigma Diagnostic (1990) Quantitative Enzymatic Determination of Pyruvate in Whole Blood at $340 \mathrm{~nm}$. Sigtna Chemical Company, St. Louis.

Sprouse G. and Rittmann B. E. (1990a) Colloid filtration in fluidized beds. J. Environ. Eng. 116(2), 299-313.

Sprouse G. and Rittmann B. E. (1990b) Colloid removal in fluidized-bed biofilm reactor. J. Environ. Eng. 116(2), 314-329.

Standard Methods for the Examination of Water and Wastewater (1989) 17th edn. American Public Health Assoc., American Water Works Assoc. and Water Pollution Control Fed, Washington, DC.

Turekian K. K. (1977) The fate of metals in the oceans. Geochim. Cosmochim. Acta 41, 1139-1144.

Verwey E. J. W. and Overbeek J. Th. G. (1948) Theory of the Stability of Lyophobic Colloids. Elsevier, Amsterdam.

Westall J. C., Zachary J. L. and Morel F. M. M. (1976) MINEQL, a computer program for the calculation of chemical equilibrium composition of aqueous systems. Tech. note 18. Dept. of Civil Engr., Mass Inst. of Tech., Cambridge, MA. 